\title{
ТВОРЧЕСТВО ДАШИ НАМДАКОВА В КОНТЕКСТЕ ПРОЦЕССОВ СОВРЕМЕННОЙ ХУДОЖЕСТВЕННОЙ КУЛЬТУРЫ
}

\author{
М. Л. Ткачева \\ Байкальский государственный университет, г. Иркутск, Российская Федерация
}

Информация о статье

Дата поступления

4 декабря 2017 г.

Дата принятия к печати 28 фревраля 2018 г.

Дата онлайн-размещения 30 марта 2018 г.

\section{Ключевые слова}

Скульптура; пленэрная скульптура; Даши Намдаков;

мифология; «Вселенная кочевника»; ювелирное искусство; имидж; художественная фрорма; художественный процесс

\begin{abstract}
Аннотация
Рассматриваются особенности творчества скульптора, ювелира и художника Даши Намдакова. Проводится мысль о своеобразии его жизненной позиции и творческих установок в связи со своеобразием функционирования современной художественной культуры. Анализируются следующие аспекты современной художественной ситуации: творческий характер художественного восприятия; репрезентативный характер личности художника; зависимость художественного творчества от экономических процессов. Делается акцент на фрормообразующем характере и внутренней противоречивости мифологического сознания для художественного процесса, на роли художника в восстановлении целостности мировосприятия современного человека.
\end{abstract}

\section{DASHI NAMDAKOV'S ART IN THE CONTEXT OF CONTEMPORARY ARTISTIC CULTURE}

\author{
Marina L. Tkacheva \\ Baikal State University, Irkutsk, the Russian Federation
}

\section{Article info}

Received

December 4, 2017

Accepted

February 28, 2018

Available online

March 30, 2018

\section{Keywords}

Sculpture; plain-air sculpture;

Dashi Namdakov; mythology;

«A Nomad's Universe»; jewelry;

image; artistic form; artistic

process

Данная публикация оформилась как обобщение нескольких интервью автора с Даши Намдаковым, взятых в период с 2007 по 2017 г., материалов о его выставках, состоявшихся в Санкт-Петербурге, Москве, Красноярске, Иркутске в тот же период, а также как результат использования искусствоведческих материалов к персональным выставкам Д. Намдакова, выпущенных Государственной Третьяковской галереей (2007) [1] и Историческим музеем (2014) [2].

\section{Контексты}

Контекст первый. Когда я пересматривала опубликованные материалы, то постоянно натыкалась на фразы журналистов вроде «спокойный», «уравновешенный», «мягкий». При довольно многочисленных встречах я могла убедиться, что внимание к миру и окружающим людям, выдержанность, интеллигентность - естественные проявления его натуры, столь же органичные, как и его одаренность. Даши красив, силен, пласти- 
чен, пропорционально сложен. Движения его выверенны, плавны. Он естественен и аристократичен в самом полном смысле слова: многовековая национальная культура и постоянное напряжение трудной работы скульптора в его поведении органично сливаются, образуя синтез. Можно сказать, что он - один из совершенных образцов человеческой породы, созданных тысячелетними усилиями трудного сосуществования людей с требовательной природой и озаренных светом ума и духа. Это, конечно, черта характера, но также и деталь имиджа, которая осознается в качестве необходимого элемента бытия художника в мире современного искусства. Неоднократно я была свидетелем того, что достаточно известные люди искусства предпочитали пренебрегать имиджевой стороной своей деятельности. В этом случае формировался образ некоего анахорета, далекого от забот реальной жизни и целиком погруженного в творческие поиски. Такая несовременная модель поведения зачастую вызывает несколько ироническое отношение к личности художника. Наиболее уместной она кажется у людей, которые занимаются творчеством без оглядки на правила и руководства выставкомов, музеев, академических проектов и одобрение искусствоведов. В «свободное от работы время» по внутренней потребности, внутреннему импульсу человек стремится «все делать сам». Большинство таких художников считает занятия творчеством средством сохранения целостности собственной личности; для них художественный опыт - прежде всего опыт экзистенциальный, который переживается отнюдь не по законам искусства и противится любому тиражированию. «Выводя наружу» свой внутренний мир, художник утверждает свою индивидуальность и значимость. Именно поэтому картины и другие работы становятся «как дети», с которыми невозможно расстаться, ведь это означает утрату части себя.

Но современная ситуация требует иного, и возникает противоположная модель личности: чрезмерное внимание к имиджу и фрормам реализации популярности, опирающимся не только (и, может, не столько) на профессионализм и талант, сколько на продаваемость и «понятность». Поддерживается вполне современное представление, что художники «отличаются от остальных, занимаясь творчеством особого, таинственного свойства. Тем не менее в той области творчества, которую часто называют искусством, есть нечто особенное. Создание и (или) исполнение историй, песен, образов, стихотворений, шуток и т.д., вне зависимости от технологической формы, предполагает креативность особого типа - манипулирование символами в целях развлечения, передачи информации или, возможно, даже просвещения» [3]. Популярность, мода, тиражируемость, рейтинги - сопутствующие фракторы такого менталитета и образа жизни. Бытие современного искусства парадоксально в том смысле, что произведения и художники, считавшиеся ранее элитарными, ориентированными на изысканный вкус профессионалов, вдруг приобрели «широкую популярность в узких кругах», обеспечивающую им известность и безбедное существование. «Продаваемость» же искусства стала индексом общепризнанности, общепонятности и обыкновенности, удаляя от формально-художественного поиска. Собственно внутрихудожественная элитарность перекочевала на противоположный полюс, туда, где никого не поддерживают, каждый «варится» в своем опыте и своих переживаниях, - на полюс самодеятельного андеграундного искусства.

Между этими двумя крайностями достаточно трудно установить точку равновесия. Необходимость саморепрезентации своего творчества, выступая особенностью современного художественного пространства, проявляется в том, что художники постоянно подчеркивают - преднамеренно или бессознательно - сходство произведений со своим внешним обликом. У меня была возможность оценить, какое значение имидж имеет для сегодняшнего художника: зрители, искренне увлекающиеся современным искусством и впервые столкнувшиеся с работами Даши, отмечали в первую очередь его внешность, а потом уже качество его работ. Более того, и интерес к искусству Даши у них возникал по причине его человеческой привлекательности. Но «случай Даши» все-таки иной: по его высказываниям можно судить, что необходимость «представительства» принимается им как данность, без раздражения и рисовки: «я считаю, что обязан оставаться в мире бурятского искусства. И делаю это абсолютно осознанно. Надеюсь, что не буду уходить от этой темы. Почему я этим занимаюсь? Посмотрите на меня, на мою внешность - как я могу по-другому? Я вырабатываю язык, который мне больше всего подходит. Настроения всех работ - это я сам. А потерять себя - это надо сильно постараться... Я обычно не говорю о деньгах, но сейчас, видимо, созрел для такого разговора. Сейчас я чувствую, что могу это. Кроме того, очень много замыслов: предоставленная мне в 
Лондоне территория позволяет собрать там команду мастеров, с которыми я давно работаю, чтобы продолжать проекты и осуществлять новые. Неудач я уже не боюсь, а сил хватает. Своими делами я занимаюсь сам. Современному художнику для успеха и реализации, да и просто для нормального существования, нужно иметь какие-то бизнес-данные. Сколько талантливых моих сокурсников не реализовались, потому что не нашли способа организовать свою раскрутку и выставки! Конечно, у меня есть большая команда помощников, но общие и важные вопросы я решаю сам. Совмещать это и оставаться художником очень сложно: развиваться, удивлять мир, а параллельно заниматься своими делами - это серьезная проблема. Мы сами себя финансируем. На содержание команды, на производство уходят миллионы долларов. Но семью свою я прокормлю в любом случае.

У меня ювелирная компания, мы много лет создаем свою коллекцию, сейчас выходим на серьезный уровень: планируем строить свой ювелирный дом в самом центре Лондона, там, где давным-давно обосновались Картье, Булгари, Сотбис. Реально потрачены астрономические суммы на реализацию Дома Даши.

После Индии я загорелся культурой камня. Я чувствую, что меня влекут большие цветные камни, самые крупные из тех, которые есть сегодня. Это камни с выставочной судьбой. Я двигаюсь в сторону ювелирной скульптуры. Эти вещи будут в единичном экземпляре, поскольку сами камни уникальны. Но работать только на фрирмы мне неинтересно, потому что это рутина, поточное производство. А У меня много амбиций, у меня такие проекты - никакая фрирма этого не выдержит. Мне говорят, что я слишком разбрасываюсь, что надо сосредоточиваться на чем-то одном, чтобы было вроде визитной карточки. Мне это чуждо. Делать одно и то же всю жизнь неужели это может быть кому-то интересно? Любую другую пластику могут делать другие. А кто будет делать мою работу, которую должен делать я?» (из интервью).

Сущность выдающегося мастера резонирует со всеми темами, которые находятся в поле внимания современников: самородок, которому, к счастью, удалось сохранить оригинальность; шаман-художник, принадлежащий современности и прошлому одновременно; человек мира, безгранично преданный родовым корням, семье, своей земле и традициям. Гений невыразим, но может выражать все, а его образы укорене- ны везде и легко поддаются интерпретации воспринимающего.

Контекст второй. Большинство авторов публикаций обязательно упоминают, что Намдаков родился в маленьком поселке Забайкалья. Фантастическая траектория его успеха, начавшаяся с персональной выставки в Иркутске (2000 г.), в глазах рядового зрителя обозначает ценность мнения столичных сообществ, экспертные мнения которых закрепили, а отчасти создали имя и репутацию Даши. Для самого же скульптора жизнь в культурных и административных столицах расширение возможностей, увеличивающих его творческий диапазон, позволяющих свободнее фантазировать и точнее осуществлять замысел: «Ведь Иркутск - город самодостаточный. Это золотая середина, не удаленные места. Он вроде и поднимает людей, делает им репутацию, но и «выталкивает», отправляет в другую, огромную жизнь, предлагает помериться силами с миром. Я хочу делать биеннале: приглашать всех творческих людей, личностей интересных. На мою репутацию уже многие «купятся». Авторитет работает: меньше надо убеждать, меньше пробиваться через стену власти» (из интервью).

Значение «случая Даши», помимо неоспоримости утверждения его творческой индивидуальности, заключается В кардинальном изменении акцентов понимания соотношения столичности и провинциальности. Традиционный контекст опровергается, традиционные отношения столицы и провинции переворачиваются: теперь, во многом благодаря активности Намдакова, становится очевидно, что провинция - особый мир, оригинальный и первичный по отношению к любым снобистским мнениям и экспертным оценкам. Популярность темы кочевников и Чингисхана также подпитывается культурными инициативами художников, подобных Намдакову, и им самим.

Контекст третий возникает из названия и сути наиболее интересного проекта Намдакова - «Вселенная кочевника». Она связана также с работой в качестве главного художника фильма «Монгол». Идея состояла в совмещении скульптур и археологических материалов, т. е. в создании для скульптур именно того культурного окружения, в контексте которого их смыслы будут прочитываться наиболее адекватно. Вселенная глобальное явление, охватывающее все без исключения, явление целостное и законченное. Поэтому, воспринимая ее краешек, отдельные предметы, зритель мысленно может объединять их, реконструировать ее 
гармонию. Предметы экспозиции создают атмосферу подлинности и представляют самостоятельную ценность, одновременно являясь своеобразным пьедесталом для собственных работ мастера. Название ассоциативно связывает нас с достижениями кочевых народов и, конечно, в первую очередь с образом и славой «человека второго тысячелетия» - Чингисхана. Протягивается ниточка к уже устоявшемуся, признанному авторитету, обретшему мировую известность и резонанс: «Мы вместе с Бодровым поехали в Тибет, в Монголию, лазили по горам, по деревням, подальше от туристических троп, там, где мало цивилизации. В Тибете вообще время остановилось. Удивительно: я много знал о Тибете, но, когда поехал туда и целенаправленно попал в эту деревню, в глушь... оказалось, что есть такие места... время остановившееся, так красиво! Такие красивые люди, фрактура одежды! Правда, в горах нехватка кислорода, дети все в язвочках, болеют, но они к этому привыкли. И Бодров говорит: «Вот что нам надо». Мы фотографировали, да и просто покупали вещи, которые потом вкладывали в картинку... Наша задача была передать эпоху, время» (из интервью).

Так происходит конструирование системы сигналов, устанавливающих традицию и указывающих, в каком именно ключе произведения скульптора должны быть прочитаны.

Контекст четвертый. Намдаков появился очень вовремя: на волне чрезвычайной популярности разговоров об архетипах, легенд о проникновении в потустороннее, шаманских предсказаний и предназначений. Его биография как бы подтверждает существование запредельного: тяжелая детская болезнь, чудесное выздоровление, предназначение быть художником, а не ламой или буддистом-отшельником, высказанное шаманами... Сегодня чрезвычайно велика мода на этнографию, нечто невиданное и экзотическое. Возрастание интереса к предметам культуры, чуждой для Европы, стало буквально «маркой» XXв. Этнографические элементы, связанные с непривычным образом жизни, ее трудностями, специфическими приметами этнических особенностей и типов, привлекают все большее внимание. Но конвергенция, которая представляется как сближение путей Африки и Европы, Запада и Востока, происходит в плоскости и пространственной, и исторической. Проект «Вселенная кочевника», и все творчество Намдакова в эту тенденцию хорошо вписалось.

Он обращается к истории, но не в привычной форме повествования, а в образах; он ищет «историю сейчас». Тот фракт, что где-то время остановилось, его не смущает, а вдохновляет, обозначая область незыблемого. Реальность прошлого удостоверена данностью материальных, весомых предметов, пришедших из богом забытых мест и эпох. Его связь с настоящим подтверждается положительным чувством, с каким мы их воспринимаем. Создавая новые ценности в традиционных формах, Намдаков творит связи с прошлым, и они становятся реальностью для современного сознания.

Таким образом, все тематические нити, которые зависят не столько от самого искусства, сколько от социального контекста его существования, стянуты в узел должным образом и с должной силой, благодаря чему создан необходимый фон для яркой звезды дарования Даши.

\section{Форма, помощники, единомышленники, ученики}

Вспоминаю, с каким огорчением на своей первой выставке Намдаков говорил, что половину скульптур пришлось выбросить из-за брака при отливке. Сразу вспоминаются его слова о сотрудничестве с итальянскими мастерами. По сути, это - только начало разговора о возвращении ремесленных способов организации творческой деятельности и об их необходимости для реализации потенциала яркой индивидуальности. Неудивительно, что центры ремесел - наиболее подходящие места, где художник находит понимание и поддержку. Сам он, выходец из деревни, прекрасно знает цену работ, рождающихся как бы «сами собой». Имя Даши - вершина айсберга; само «тело» - горы, огромное число помощников, мастеров, производящих доводку замысла, скрыто от публики. Креативность лидера, переливающаяся в мастерство и изобретательность его помощников, - самостоятельная проблема, прямо соотносящаяся с характером современного искусства больших форм.

Изобретением, созданием эскиза и даже изготовлением скульптуры и ювелирного изделия творческий процесс не заканчивается. Вряд ли можно представить себе скульптора, который создает свои работы «для себя», «в стол», как это бывало с авангардной живописью еще сто лет назад. Завершение замысла - это подготовка выставочной экспозиции, в которой даже устройство витрин не может быть второстепенной деталью: оно требует специальной заботы и изобретательности, чтобы соответствовать современным требованиям. Присутствие в музейных залах скульптур Намдакова вызывало отчетливое 
чувство неуютности, странности. Только спустя время вдруг прояснилось существенное обстоятельство: открытая, обнаженная архитектура залов, арки и своды, цвет стен и пола так же необходимы для полноты впечатления, как и высокое качество отливки самих скульптур. Организация такой экспозиции требует специальных навыков и большого таланта: нужно соотнести масштабы будущей экспозиции с размерами экспозиционных пространств, количество и пропорции самих работ, расстояние между ними и массу других необходимых, но непроговариваемых элементов. Вряд ли было бы возможно более выверенно и скрупулезно разместить в залах разные по настроению, размерам, содержанию работы. И если каждая нашла место, соразмерное замыслу и масштабам, то это заслуга людей, работающих в команде Даши.

Интуиция об уместности скульптуры в том или ином месте - это часть ее художественной формы. "Стихия», установленная в музейном зале и на валуне у стен Казанского кремля, по-разному раскрывается и звучит. И по-особому ощущается отвага, стремление к риску, которые побуждают скульптора выйти за пределы музейных стен, в открытое пространство, для которого они выглядят как естественный и органичный центр, «гений места». На вопрос о значении пленэрных скульптур Намдаков ответил: «Очень интересно, я получаю колоссальный драйв от этого. Если я делаю выставочную скульптуру, я как бы говорю: понимаете вы меня или нет - это мой мир, это мои идеи, извините, это мое творчество, я так чувствую и вижу. А вот когда я делаю для открытого пространства - это гораздо сложнее; возникает масса нюансов и обязательств - человеческих и социальных. Естественно, я берусь за те вещи, которые меня интересуют. Я не люблю комментировать свои работы, да это, наверное, и невозможно. Знаю только одно: все, что создается в среде, должно доставлять эстетическое удовольствие. Мне не всегда понятно, как вживутся или не вживутся мои работы в городскую среду. Но если бы было до конца понятно, то было бы и неинтересно. Знаю только, что самая убийственная характеристика для любой скульптуры - это когда она стоит, а ее никто как бы и не замечает. Это как же должен замылиться глаз, чтобы монументальные объекты выглядели ничем, как это иногда случается?

У меня была интересная история с «Горной Шорией». Место - Алтайская гряда, Саяны. Мне нужна была Хозяйка. Девушка на лосе выходит из тайги, у сохатого огром- ные лопасти рогов, а на них - петроглифы тех мест. Там у нее на груди символ солнца, в руках чаша - символ гостеприимства. После разговора с губернатором я вечером нарисовал эскиз на салфетке, вокруг написал комментарий и объяснения к ней. И улетел в Новосибирск, а потом в Иркутск. Иподзабыл эту историю. Вдруг звонит губернатор: все, ставим. Он согласился с концепцией; ведь это - создание истории скульптуры, а такая вещь сама строит репутацию и власти, и месту. Тулеев согласился, что отливать надо в Италии: пусть будет дорого, но качественно. После отливки итальянские мастера попросили выставить ее в городе. Мы поставили ее на время в роскошном сквере. Вокруг классическая итальянская архитектура, южная природа. Там сделали небольшую выставку моих работ. Я посмотрел на «Шорию» - и так она мне не понравилась! И перед губернатором неудобно, что работа получилась вроде плохая. Мне надо было ехать на открытие «Шории» в Кемеровскую область, когда уже снег выпал. Я приезжаю с таким плохим настроением - как же я в лицо буду смотреть губернатору за плохую работу? Смотрю - волшебно!!! Она приехала домой, как хозяйка приехала - и встала на место» .

Овладение секретами формообразования - самая «техническая» сторона творчества. В истории не единожды бывало, что франтастические достижения художников, скульпторов, архитекторов становились своеобразной школой для следующего поколения (Болонская академия). И всякий раз школа начиналась с овладения техникой. Учитывая, что такие навыки передаются практически всегда «из рук в руки», в непосредственном взаимодействии, общении, обучении, следовало бы ожидать, что у Даши есть ученики. Есть ли они?

По существу, необходимость и стремление передать свой опыт - признак именно ремесленной и классической художественной традиции. Современное искусство, ориентированное на постоянные инновации, вряд ли приспособлено для создания художественной школы, ибо любая школа - это осмысление и развитие созданного мастером. В настоящее же время каждый интересный (а тем более выдающийся) художник скорее опровергает, чем продолжает предшественников.

Когда-то, еще в XVIII в., И. Кант писал, что гений - это «образцовая оригинальность природного дарования субъекта в свободном применении своих познавательных способностей», в создании художественных произведений [4]. Необходимость гения, т. е. художника, создающего подлинное искус- 
ство, диктуется самой его природой: гений не может реализоваться в вещах, которые подчиняются какому бы то ни было правилу. Он создает то, для чего нет определенных правил, не отдавая ни самому себе, ни другим отчета о том, как появляются идеи его произведений; они как бы и есть сама природа. Произведения гения сами должны стать примером для подражания. Таким образом, вряд ли стоит ждать от Намдакова учительства в классическом смысле; скорее, его влияние будет сказываться в самых неожиданных и не связанных прямо с его работами направлениях и вещах.

\section{Мифология и образы}

Сегодня стало привычным говорить и писать вслед за Юнгом, что «художественное произведение надо рассматривать как образотворчество, свободно распоряжающееся всеми своими исходными условиями». Но в любом акте творения видны «следы прошлого», и человеку «кажется, что он плывет, тогда как его уносит невидимое течение» [5, с. 274]. В скульптурах, графике и украшениях Даши прорывается надличностная сила, рождающая странные образы и формы, ускользающие от четкой работы мысли. Возможно, причина их популярности коренится не только в совершенстве формы и отделки, но и в органичной, невидимой с первого взгляда традиционности. Усилием воли древний человек создавал из хаоса и угроз мира форму, красоту, мудрость, соединял разные смыслы и явления, которые по логике "разумного», современного мира должны быть обособлены. В небольшом презентационном фильме один из профессоров американского университета говорит, что две тысячи лет назад Даши был бы шаманом, тысячу лет назад - ламой, а сегодня он - художник.

Закостеневшая структура жестких оппозиций, утверждения и отрицания, добра и угрозы прорывает плотину стихии архаического бессознательного, превращаясь в нечто текучее и двусмысленное. В этом мире нет неодушевленных предметов или сил; его пространство насыщено одновременно покоем и движением, оно нестабильно, трансформируется на глазах, а потому покой существ, находящихся внутри него, оказывается мнимым и временным. Но у превращения есть и свои законы. Звери ли превращаются в человека или он - в зверя? «Он» и «Она» Намдакова - то ли копытные животные, то ли люди в природной телесности. «Жемчужина» - девушка-раковина. «Видение» - то ли лань, то ли женщина. Примеры можно множить и множить. Этот баланс на грани зооморфных форм сродни мифу и совершенно очевидно коррелирует с сюрреалистическими экспериментами, основной мотив которых - превращение, промежуточные формы жизни, двусмысленность и неразличимость явлений. Из всех персонажей XX в. Даши наиболее близок Сальвадору Дали по степени убедительности его образов и способности делать незаметным зазор между реальностью и фантастикой, парадоксальностью и наглядной достоверностью.

Но в одном наш герой не похож ни на кого: у него отсутствует ирония и сопутствующая ей некоторая «корявость» материальной формы, столь типичные для современного искусства в целом; он прост и естественно серьезен. Это взгляд ребенка со стихийно, сами собой возникающими переходами от реальности к достоверной франтазии, который сочетается с духом мудреца и дополняется неоспоримой подлинностью предметного воплощения творческого замысла. Нигде Намдаков не погрешил против главного требования искусства высокого стиля: каждая из его работ, будь то конная статуя или кольцо, прекрасна, доделана до максимально возможной степени совершенства.

И все-таки от его работ веет опасностью, скрытой за оболочкой прирученной красоты стихийной угрозой. Раскоряченные, распластанные по земле стреляющие воины; черепа, отшлифованные ветрами и водой до зеркального блеска; невиданные или узнаваемые насекомые, намертво схватившие когтями драгоценные камни; оскалившиеся звери и неведомо что видящие шаманы... Здесь не изжиты, но облагорожены тревога и смерть, некая почти первобытная ментальность, специфические особенности родоплеменного мировосприятия, психологии, концепции человека и общества.

Излюбленные сюжеты и образы Намдакова - женские. Мне кажется, что именно в них пересекаются пути и замыслы его творчества. Многообразны ипостаси женских скульптур, их внутренняя полнота. Под полнотой я подразумеваю противоречивость, наличие обязательных качеств - свирепой защиты своей территории (рода) от врагов и нежной агрессии, изящной силы и мощной беспомощности, утонченной красоты и материнской основательности. В женских образах - символе души - сливаются образы матери, возлюбленной, жены, сестры, дочери; вечные возвращения вечной женской натуры. Профриль амазонки - это выражение и героизма, и невозмутимости, и романтич- 
ности, и спокойствия. Она хранительница, но приходит опасность - и она надевает шлем, превращается в кошку, пантеру. Наверное, как и любая женщина. Она напоминает античные образы, но маска-шлем пантеры отсылает к образам антропозооморфным, доклассическим.

Невеста на коне богата не деньгами и драгоценностями. Музыкальный инструмент за спиной, в сундучке - свитки книг, сверху примостилась дворцовая собачка. Вся фригура вместе с лошадью вписывается в овал идеальный контур для восприятия.

Для сохранения жизнеспособности монументальной скульптуре уже недостаточно быть закреплением идеологических импульсов и напоминанием об исторических событиях. В полном соответствии с духом времени она впитывает мифологические токи, взбаламучивая коллективное бессознательное, синкретически отзывающееся на разломы времени и пространства. Даши не занимается идеологией в привычном смысле, никакой истории не пишет. Совсем иначе выстраиваются его отношения с мифологией, с современным способом закреплять архетипические смыслы. На первый взгляд его возвращение к прошлому эклектично: мотивы разных эпох и культур встречаются в едином поле его фантазии; он свободно оперирует иранскими, китайскими, египетскими, бурятскими, монгольскими сюжетами и символами, прямо, однако, ничего не заимствуя. Это, безусловно, примета современности, для которой индивидуальность наивысшая ценность. Эта же индивидуальность скрепляет, восстанавливает единство из культурных «обломков и мотивов»: в его исполнении полузабытые смыслы символов оживают, со всей серьезностью и неистовостью пробуждая родовую память человека, подчеркивая ее общие для всех народов корни. В скульптуре огромного быка (Астана), по словам самого художника, его образ должен восприниматься «как символ Казахстана: мощный, стабильный, как дубовый стол, как казахстанская земля, несгибаемый, стоящий на прочных ногах. Ковер, который натянут на его спину, выполнен в «зверином» стиле: там и смена сезонов, и орнамент из летящих коней - все в центральноазиатских традициях. Вместо ножек трона с четырех сторон - архары. Два барса, стоящих на троне, - государственный символ Казахстана, святые животные; они держат меч. У самой царицы не должно быть никакого оружия. Пусть меч будет, но как средство защиты, как завещание жить в мире. Я горд, что мне удалось реализовать этот замысел. Эта скульптура хоть и монументальная, она совсем другая, чем нас учили. Но я думаю, что она войдет в анналы. Замечательно, что Нурсултан Назарбаев отозвался на мое условие - не мешать во время работы; я считаю, что только так и может получиться что-то значительное. А по-другому работать и смысла не имеет» (из интервью).

Обобщенность, заложенная в самом корне творчества «степного Дали», ощущается не только в трактовке образов, но и в смешении разных мифологических традиций. Мифы не зря называют образным воплощением коллективного бессознательного: они перетекают друг в друга, являясь универсальным языком культуры древности. Сам он чаще называет основу своего творчества не мифологией, а философией. Вот «Четверо дружных» (пос. Агинское): у слона уши - крыло дракона; клыки растут из пасти дракона, а не слоновьей пасти. По боку слона гравирована ленточка, которая на самом деле дракон - символ Вселенной. Мышцы одновременно - облака, внизу, на поверхности земли, баранчики пасутся. На ногах слона вроде когти (тоже драконьи), а поближе подойдешь - там кони просматриваются. В общем, как говорит сам автор, «здесь воплощается очень древняя фрилософия: каждый по отдельности не достал бы ничего, только общими усилиями можно успешно завершить дело. Так слон, обезьяна, заяц и птица добывают плод и делятся друг с другом. Это очень близко самому духу Аги: объединение - благо. Я долго придумывал что-то, а после разговора с ламами все стало ясно. Ничего не надо выдумывать, надо воспользоваться уже сложившимися образами. Слон, как и дракон, - это наша Вселенная, наша земля. Мышцы превращаются в облака, в космос. Изображение открывается как книга, и прочесть ее дано внимательному читателю. Это книга, где пишется твоя история» (из интервью).

Как современная, так и классическая мифология никак не предполагает пассивности: они обязательно настраивают либо на наше собственное действие в качестве участников, либо на личное присутствие при действии. Присутствие обязательно предполагает сопричастие, партиципацию: «Я смотрю, ощупываю, переживаю и - тем самым - участвую, так как "завожу» участников-зрителей». Сопричастие двойственно: оно как позитивно, так и провокативно, возбуждает агрессию, беспокойство, провоцирует тревогу, причиной которых является «подвижная конфигурация 
городских пространств, ситуаций и практик». Среди смыслов города, большая часть которых никогда не возникла бы в традиционных устойчивых сообществах, обнаруживаются, по словам Баумана, «вкрапления страха в повседневную жизнь». В таких случаях особый смысл приобретает то качество скульптур Намдакова, которое критики с восхищением называют «покоем», «остановившимся мгновением, которое может длиться вечно». Яркий пример - скульптура «Полет», которую предполагается поставить в Улан-Удэ. Конь устремился вверх, а на его спине прижался к шее и обхватил ее руками щуплый мальчишка. Эта, казалось бы, простая по идее вещь захватывает: в ней ощущается неустойчивый баланс силы и слабости, надежда на хорошее будущее.

Так скульптура являет собою место умиротворяющего диалога сообществ, доминанту равновесия социальных сил, соединение пространства-существования и времени-прохождения, в высокой степени присущих кочевым культурам.

Художник «сшивает» своим дарованием противоречивость бытия современного искусства, впитывающего токи расколотого мира, по-своему восстанавливает утраченную этим миром гармонию, удерживая и не теряя его сложности и конфликтности.

\section{Попытка итоговой рефлексии}

Намдаков стоит между эпохами - эпохой классики, когда считалось, что искусство должно быть академично-профессиональным, и эпохой современности, когда из музейного и выставочного искусства требование профессионализма утекает в область прикладных, пограничных занятий (ювелирные изделия, дизайн ит. п.). Художник, глубоко современный по мировосприятию, он формирует новый тип творчества классическое по форме, авангардное (но историческое) по содержанию. В таком сочетании коренится противоречие, запрограммированное особенностями сегодняшнего состояния художественной культуры, и определяемые им риски.

Контекст этого состояния описан еще Э. Тоффрлером в его работе «Шок будущего» [6]: сейчас вырастает поколение, кото- рое не может ничему научиться у своих родителей; следовательно, современная культура не столько наследует классической, сколько отрицает ее, конструируя совершенно новые фрормы. Кроме назойливого креатива, становится нормой не высокий профессионализм (вспоминая Аристотеля, можно выразиться его словами: «умение искусно изображать лицо»), но скорее умение «изображать прекрасное лицо» (=современную интерпретацию эстетического идеала). Таким образом, критерии художественности размываются: место профессионализма и технического совершенства (их вполне могут предоставить современные технологии) занимает стремление создать такое новое произведение, направление, идеологию, которые раньше не встречались. Тотальная инновационность соприкасается с тем, что сама художественная деятельность оказывает достаточно ограниченное влияние на реальные процессы социального бытия, удовлетворяясь самодостаточностью, «самоговорением». Итак, традиционное представление, что «искусство не только отражает жизнь, но и творит ее», создавая такую систему смыслов, которая никак не осуществляется, вполне реализуется: искусство остается жить лишь в виртуальных фрормах деятельности. Понятно, что вышеупомянутая особенность - логическое завершение весьма популярного в идеологии еще XIX в. принципа «искусства для искусства».

Но если художники ориентируются на добротный профессиональный уровень творчества в технике и темах, то они рискуют остаться художниками элитарными, понятными и востребованными лишь малой категорией «воспитанных» зрителей, читателей и слушателей. К такой элитарной культуре все более относится классическая культура и классическое искусство как ее наиболее концентрированное воплощение. Старые мастера XX в. - это чуть ли не последний всплеск классической культуры, стремящейся удержать целостность картины мира и ее художественного воплощения. Наш герой виртуозно преодолевает риски, обозначенные выше. Его биография столь стремительно и в то же время естественно насыщается новыми формами и темами, что трудно уследить за ее поворотами и скоростью.

\section{СПИСОК ИСПОЛЬЗОВАННОЙ ЛИТЕРАТУРЫ}

1. Даши Намдаков. Скульптура, графика, ювелирное искусство / ред. Н. П. Комарова, Л. В. Марц, Э. Э. Уланова. - М. : М-Сканрус, 2010. - 160 с.

2. Кочевник. Между небом и землей. Шедевры древних культур степей Евразии из собрания Исторического музея и произведения скульптора Даши Намдакова / Н. Жуковская [и др.]. - М. : Гос. ист. музей, 2014. - 320 с. 
3. Хезмондалш Д. Культурные индустрии / Д. Хезмондалш ; пер. с англ. И. Кушнаревой ; под науч. ред. А. Михалевой. - 2-е изд. - М. : Высш. шк. экономики, 2018. - 456 с.

4. Кант И. Критика способности суждения // Сочинения : в 6 т. : пер. с нем. / И. Кант - М. : Мысль, 1966. - T. 5. -564 c.

5. Юнг К.-Г. Архетип и символ / К.-Г. Юнг ; сост. и вступ. ст. А. М. Руткевича. - М. : Ренессанс, 1991. $-304 \mathrm{c}$.

6. Тоффрлер Э. Шок будущего : пер. с англ. / Э. Тоффрлер. - М. : АСТ, 2002. - 557 с.

\section{REFERENCES}

1. Komarova N. P., Marts L. V., Ulanova E. E. (eds.). Dashi Namdakov. Skul'ptura, grafika, yuvelirnoe iskusstvo [Dashi Namdakov. Sculpture, Graphics, Jewellery]. Moscow, M-Skanrus Publ., 2010. 160 p.

2. Zhukovskaya N. [et al.]. Kochevnik. Mezhdu nebom i zemlei. Shedevry drevnikh kul'tur stepei Evrazii iz sobraniya Istoricheskogo muzeya i proizvedeniya skul'ptora Dashi Namdakova [Nomad. Between Heaven and Earth. Masterpieces of Ancient Cultures of Eurasian Steppes from the Collection of the Historical Museum and Works of the Sculptor Dashi Namdakov]. Moscow, State Historical Museum Publ., 2014. 320 p.

3. Hesmondhalgh D. The cultural industries. $2^{\text {nd }}$ ed. Los Angeles, Sage Publ., 2007. XIV, 346 p. (Russ. ed.: Hesmondhalgh D. Kul'turnye industrii. $2^{\text {nd }}$ ed. Moscow, Higher School of Economics Publ., 2018. 456 p.).

4. Kant I. Critik der Urtheilskraft. Berlin, 1790. (Russ. ed.: Kant I. Kritika sposobnosti suzhdeniya. Sochineniya. Moscow, Mysl' Publ., 1966. Vol. 5. 564 p.).

5. Jung C. G. Arkhetip i simvol [The Archetype and Symbol]. Moscow, Renessans Publ., 1991. 304 p.

6. Toffler A. Future shock. New York, 1970. (Russ. ed.: Toffler A. Shok budushchego. Moscow, AST Publ., 2002. 557 p.).

\section{Информация об авторе}

Ткачева Марина Львовна - кандидат философских наук, доцент, кафедра философии, Байкальский государственный университет, 664003, г. Иркутск, ул. Ленина, 11, e-mail: margo514@yandex.ru.

\section{Для цитирования}

Ткачева М. Л. Творчество Даши Намдакова в контексте современной культуры / М. Л. Ткачева // Известия Байкальского государственного университета. - 2018. - T. 28, № 1. - C. 150-158. - DOI: $10.17150 / 2500-2759.2018 .28(1) .150-158$.

\section{Author}

Marina L. Tkacheva - PhD in Philosophy, Associate Professor, Department of Philosophy, Baikal State University, 11 Lenin St., 664003, Irkutsk, the Russian Federation, e-mail: margo514@yandex.ru.

\section{For citation}

Tkacheva M. L. Dashi Namdakov's Art in the Context of Contemporary Artistic Culture. Izvestiya Baykal' skogo gosudarstvennogo universiteta $=$ Bulletin of Baikal State University, 2018, vol. 28, no. 1, pp. 150158. DOI: $10.17150 / 2500-2759.2018 .28(1) .150-158$. (In Russian). 